\title{
Rayleigh-Taylor instability: Modelling and effect on coherent deflagrations
}

Keenan, J., Makarov, D., \& Molkov, V. (2014). Rayleigh-Taylor instability: Modelling and effect on coherent deflagrations. International Journal of Hydrogen Energy, 39(35), 20467-20473. https://doi.org/10.1016/j.ijhydene.2014.03.230

Link to publication record in Ulster University Research Portal

\section{Published in:}

International Journal of Hydrogen Energy

Publication Status:

Published (in print/issue): 03/12/2014

DOI:

10.1016/j.ijhydene.2014.03.230

\section{Document Version}

Publisher's PDF, also known as Version of record

\section{General rights}

Copyright for the publications made accessible via Ulster University's Research Portal is retained by the author(s) and / or other copyright owners and it is a condition of accessing these publications that users recognise and abide by the legal requirements associated with these rights.

\section{Take down policy}

The Research Portal is Ulster University's institutional repository that provides access to Ulster's research outputs. Every effort has been made to ensure that content in the Research Portal does not infringe any person's rights, or applicable UK laws. If you discover content in the Research Portal that you believe breaches copyright or violates any law, please contact pure-support@ulster.ac.uk. 


\title{
Rayleigh-Taylor instability: Modelling and effect on coherent deflagrations
}

\author{
J.J. Keenan*, D.V. Makarov, V.V. Molkov \\ Hydrogen Safety Engineering and Research Centre (HySAFER), University of Ulster, Shore Road, Newtownabbey, \\ Co. Antrim BT37 OQB, UK
}

\section{A R T I C L E I N F O}

Article history:

Received 16 January 2014

Received in revised form

14 March 2014

Accepted 28 March 2014

Available online 25 April 2014

\section{Keywords:}

Deflagration

Modelling

Rayleigh-Taylor instability

Venting

\begin{abstract}
A B S T R A C T
The modelling of Rayleigh-Taylor instability during premixed combustion scenarios is presented. Experimental data obtained from experiments undertaken by FM Global using their large-scale vented deflagration chamber was used to develop the modelling approach. Rayleigh-Taylor instability is introduced as an additional time-dependent, combustion enhancing, mechanism. It is demonstrated that prior to the addition of this mechanism the LES deflagration model under-predicted the experimental pressure transients. It is confirmed that the instability plays a significant role throughout the coherent deflagration process. The addition of the mechanism led to the model more closely replicating the pressure peak associated with the external deflagration.

Copyright @ 2014, Hydrogen Energy Publications, LLC. Published by Elsevier Ltd. All rights
\end{abstract} reserved.

\section{Introduction}

The goal of this study is to understand the role of Rayleigh-Taylor (RT) instability within the underlying physical phenomena associated with coherent deflagrations. Following from this, a Large Eddy Simulation (LES) modelling approach, including a mechanism to account for RT instability, has been developed utilising the multi-phenomena turbulent burning velocity model [1,2].

During the study [3] of a hydrogen-air deflagration in the congested environment of a mock-up refuelling station [4], RT instability was identified as being the most likely missing mechanism which would, if implemented into the deflagration model, contribute to combustion enhancement in flame front areas where there was significant flame front acceleration in the direction from combustion products to the fresh mixture.

This extension of the model, to account for RT instability, was then tested against appropriate experimental results [5].

\section{Validation experiments}

The experiments as described by Bauwens et al. [5] were performed using the FM Global $63.7 \mathrm{~m}^{3}$ large scale test chamber, with a single square vent of $2.7 \mathrm{~m}^{2}$ or $5.4 \mathrm{~m}^{2}$. Ignition occurred at either the centre of the back wall or at the centre of the chamber, at a height of $1.5 \mathrm{~m}$. Hydrogen concentration in air was $18 \%$ by volume inside the chamber. Mixing fans created a uniform mixture. Ignition was supplied using a carbon rod igniter. Pressure-time histories were provided,

\footnotetext{
* Corresponding author.

E-mail addresses: j.keenan@ulster.ac.uk, jameskeenan@hotmail.co.uk (J.J. Keenan), dv.makarov@ulster.ac.uk (D.V. Makarov), v. molkov@ulster.ac.uk (V.V. Molkov). 


\begin{tabular}{|c|c|c|c|}
\hline \multicolumn{2}{|c|}{ Nomenclature } & $\Xi_{f}$ & fractal term, - \\
\hline A & Atwood number, - & $\Xi_{K}$ & self-induced turbulence term, - \\
\hline & combustion progress variable _- & $\Xi_{l p}$ & leading point term, - \\
\hline E & $\begin{array}{l}\text { expansion ratio, - } \\
\text { explions, - }\end{array}$ & $\Xi_{R T}$ & RT instability term, - \\
\hline Acc & acceleration, $\mathrm{m} / \mathrm{s}^{2}$ & $\rho$ & density, $\mathrm{kg} / \mathrm{m}^{3}$ \\
\hline$h$ & RT amplitude, $\mathrm{m}$ & $\psi$ & model constant, - \\
\hline$k_{h}$ & constant multiplier, - & $\omega$ & Perturbation growth rate, $1 / \mathrm{s}$ \\
\hline$p$ & pressure, $\mathrm{Pa}$ & Bars & \\
\hline$R_{\circ}$ & critical radius, $\mathrm{m}$ & - & LES filtered quantity \\
\hline$S$ & slanted side of cone length, $\mathrm{m}$ & $\sim$ & LES mass-weighted filtered quantity \\
\hline$S_{1}, S_{2}$ & surface area $1,2, \mathrm{~m}^{2}$ & \multirow{2}{*}{\multicolumn{2}{|c|}{ Subscripts/Superscripts }} \\
\hline$S_{c}$ & progress variable source term, $\mathrm{kg} / \mathrm{m}^{3}-\mathrm{s}$ & & \\
\hline $\mathrm{Sc}_{\text {eff }}$ & effective Schmidt number, - & $a$ & air \\
\hline$S_{T}$ & turbulent burning velocity, $\mathrm{m} / \mathrm{s}$ & $b$ & burned \\
\hline \multicolumn{2}{|c|}{$\mathrm{S}_{\mathrm{T}_{\mathrm{x}}}, \mathrm{S}_{\mathrm{T}_{\mathrm{y}}}, \mathrm{S}_{\mathrm{T}_{\mathrm{z}}} \mathrm{S}_{\mathrm{T}}$ component: $\mathrm{x}, \mathrm{y}, \mathrm{z}$} & C & source term, progress variable \\
\hline \multicolumn{2}{|c|}{$\mathrm{S}_{\mathrm{u}} \quad$ laminar burning velocity, $\mathrm{m} / \mathrm{s}$} & eff & effective \\
\hline \multicolumn{2}{|c|}{$S_{u}^{w} \quad$ SGS wrinkled burning velocity, $\mathrm{m} / \mathrm{s}$} & $\mathrm{H}_{2}$ & hydrogen \\
\hline \multirow{2}{*}{$S_{\Xi_{R T}}$} & RT factor source term, $1 / \mathrm{s}$ & $i, j, k$ & spatial coordinate indexes \\
\hline & temperature, $\mathrm{K}$ & $\mathrm{T}$ & turbulent \\
\hline $\begin{array}{l}\mathrm{T} \\
u^{\prime}\end{array}$ & sub-grid scale velocity, m/s & $t$ & current timestep \\
\hline \multicolumn{2}{|c|}{$U_{x}, U_{y}, U_{z}$ flow velocity component: $x, y, z$} & u & unburned \\
\hline$x$ & spatial coordinate, - & $w$ & wrinkling \\
\hline \multirow[t]{2}{*}{ Y } & mass fraction, - & $t-\Delta t$ & previous timestep \\
\hline & & 0 & initial conditions \\
\hline \multicolumn{2}{|c|}{ Greek } & \multicolumn{2}{|c|}{ Abbreviations } \\
\hline$\alpha$ & constant coefncient, - & $\mathrm{CV}$ & control volume \\
\hline$\Delta_{c v}$ & ignition CV size (equivalent radius), $\mathrm{m}$ & LES & Large eddy simulation \\
\hline$\Delta \tau$ & timestep, s & RNG & renormalization group \\
\hline$\Delta t_{\text {ign }}$ & Ignition time, s & RT & Rayleigh-Taylor \\
\hline$\varepsilon$ & thermokinetic index, - & SGS & sub-grid scale \\
\hline$\lambda$ & most unstable wavelengtn, $m$ & UDF & user-defined function \\
\hline $\begin{array}{l}\mu \\
\nu\end{array}$ & kinematic viscosity, $\mathrm{m}^{2} / \mathrm{s}$ & UDS & user-defined scalar \\
\hline
\end{tabular}

allowing detailed comparison with simulation results (labelled as 'Internal' in subsequent pressure-time graphs).

\section{The model overview}

The governing equations used during the simulations describing the combustion of the premixed, initially quiescent, hydrogen-air mixture are obtained by filtering the dimensional conservation equations of mass, momentum, energy and species concentration and are published elsewhere, e.g. Ref. [6].

\section{Premixed flame propagation modelling}

The transport equation for the progress variable, which is defined as the mass fraction of the products of combustion, is applied for flame propagation tracking:

$\frac{\partial}{\partial t}(\bar{\rho} \tilde{c})+\frac{\partial}{\partial x_{j}}\left(\bar{\rho} \tilde{u}_{j} \tilde{c}\right)=\frac{\partial}{\partial x_{j}}\left(\frac{\mu_{e f f}}{S c_{e f f}} \frac{\partial \tilde{c}}{\partial x_{j}}\right)+\bar{S}_{c}$.

The source term in the progress variable equation can be written using the gradient method [7] as:
$\overline{\mathrm{S}}_{\mathrm{c}}=\rho_{\mathrm{u}} \mathrm{S}_{\mathrm{T}}|\operatorname{grad} \tilde{c}|$,

where $|\operatorname{grad} \tilde{c}|$ is the gradient of the progress variable. Using this method the integral of the source term through the numerical flame front thickness gives the same mass burning rate per unit flame surface area, $\rho_{u} S_{T}$, independent of the size of cells in the numerical front. The molecular Prandtl number and Schmidt numbers are both set to 0.7 , reflecting the characteristics for air. The effective viscosity, effective Prandtl number and Schmidt number is calculated according to the renormalization group (RNG) theory [8].

Due to the large scale, real world, experimental problems investigated in this study, the effects of turbulence and combustion instabilities, including RT instability, must be modelled. This combustion model has been implemented through the utilisation of an appropriate UDF. This capability is available within the solver employed, ANSYS Fluent (13.0).

\section{Multi-phenomena turbulent burning velocity model}

The latest version of the multi-phenomena turbulent burning velocity deflagration model is described in Ref. [1] and takes into account various phenomena affecting the turbulent 
burning velocity. The equation describing the turbulent burning velocity [1] is written as:

$S_{T}=S_{u}^{w} \cdot \exp \left(u^{\prime} / S_{T}\right)^{2}=\left[S_{u} \cdot \Xi_{K} \cdot \Xi_{l p} \cdot \Xi_{f}\right] \cdot \exp \left(u^{\prime} / S_{T}\right)^{2}$,

where $u^{\prime}$ is the SGS turbulent flow velocity [9]. Eq. (3) is a modified form of Yakhot's original equation [10]. The key step in the development of this model is the substitution of the laminar burning velocity term, $S_{u}$, in Yakhot's original equation with the sub-grid scale (SGS) wrinkled burning velocity, $S_{u}^{w}$. This introduced term accounts for the unresolved phenomena affecting burning rate at all SGS lengths. It should be noted that $S_{u}^{w}$ influences the total turbulent burning rate through interaction with flow turbulence in the unburned mixture, Eq. (3).

Within the mechanisms contained within Eq. (3), the dependence of the laminar burning velocity on transient pressure and temperature is taken into account following the assumption of adiabatic compression/expansion. This requires the calculation of the thermokinetic index which is taken from Ref. [11], as $\varepsilon=0.65$. The characteristic radius at which transition to the fully turbulent self-similar regime, $R_{0}$, occurs is set to $1 \mathrm{~m}$ [12]. The 'ad-hoc' parameter $\psi$ contained with the model $(\psi<1)$ is set to 0.5 following [13].

\section{Mesh geometry, initial and boundary conditions and numerical details}

The calculation domain comprises a hemispherical area, based on the FM Global large scale deflagration facility [5]. It was meshed using an unstructured tetrahedral grid. The smallest control volumes (CVs), with an average edge size of $0.1 \mathrm{~m}$, were located inside the chamber and in the area surrounding the vent. This clearly implies the requirement for SGS modelling of unresolved combustion mechanisms. The total number of CVs was around $10^{6}$.

The boundary conditions applied were non-slip, nonpermeable, adiabatic conditions on all walls and ground surfaces. At the outer edge, non-reflecting pressure far-field boundary conditions, as implemented by ANSYS Fluent based on Riemann invariants, were applied. An unrestricted open vent was used.

The flammable mixture was initially contained inside the chamber. Air was located in the remaining area. Pressure was atmospheric. Initial temperature was $295 \mathrm{~K}$. The initial value of the progress variable was $c=0$. Inside the chamber $\mathrm{Y}_{\mathrm{H}_{2}}=0.015$ (corresponding to $18 \%$ of hydrogen by volume) and $Y_{a}=0.985$. Combustion was initiated by slowly increasing the progress variable in one CV. Duration of ignition was assumed to be equal to the flame propagation time from the centre to the edge of the ignition CV: $\Delta t_{\text {ign }}=1 / 2 \cdot\left(\Delta_{c v} / S_{u} \cdot E\right)$.

The governing equations were solved by employing a second-order accurate upwind scheme for convection terms. Following authors' experience the reduction of discretization scheme from 2 nd order to 1 st order resulted in a significant decrease of combustion rate and an underestimation of pressure peaks. Diffusion terms were central-differenced and second-order accurate. The progress variable and energy source terms were solved within the UDF. An explicit scheme was used for time stepping, the Courant-Friedrichs-Lewy (CFL) number was set to 0.8 .

\section{Simulation results prior to the inclusion of the Rayleigh-Taylor instability}

The simulation results shown in Fig. 1 were obtained using the multi-phenomena turbulent burning velocity model described by Eq. (3), termed as the 'former' model results. Also plotted on Fig. 1 are the experimental internal pressure dynamics [5].

When considering the central ignition cases, the former model failed to satisfactorily reproduce the experimental pressure dynamics [5]. However the model did show general agreement with the maximum pressures and general shape of the experimental results, when considering the back wall ignition case. It is clear from these results that the first distinct pressure peak has not been reproduced.

From the literature, including [14], the first pressure peak can be said to be caused by the external deflagration, created by the flame front emerging from the vent and propagating through the unburned highly turbulent hydrogen-air mixture which had been previously expelled from the chamber. In order for the external deflagration to have a significant influence on the internal pressure dynamics, the pressure generated externally must be comparable to or above the internal pressure. Such a pressure increase externally will reduce the pressure difference across the vent, thereby reducing venting efficiency $[1,15]$. This blocking of the outflow will cause the internal pressure to increase. Following the dissipation of the external pressure, inside the chamber the pressure will be released, generating the pressure peak. In some cases it was reported that the external deflagration can be the dominant influence on the internal pressure [16]. The authors of [5] stated (following private communication) that during the
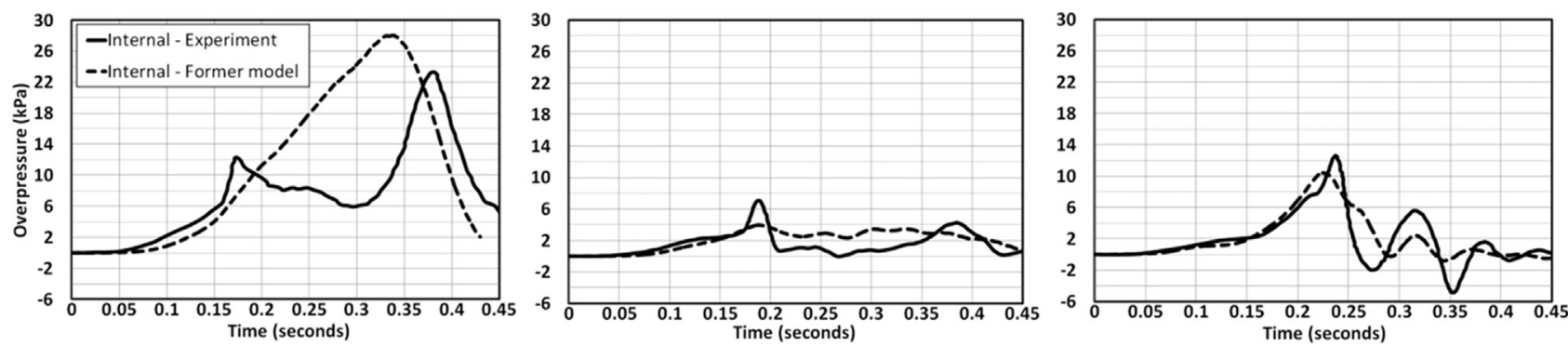

Fig. 1 - Comparison between experiment and former model simulations, central ignition case, $2.7 \mathrm{~m}^{2}$ vent (left); central ignition case, $5.4 \mathrm{~m}^{2}$ vent (centre); and back wall ignition case, $5.4 \mathrm{~m}^{2}$ vent (right). 

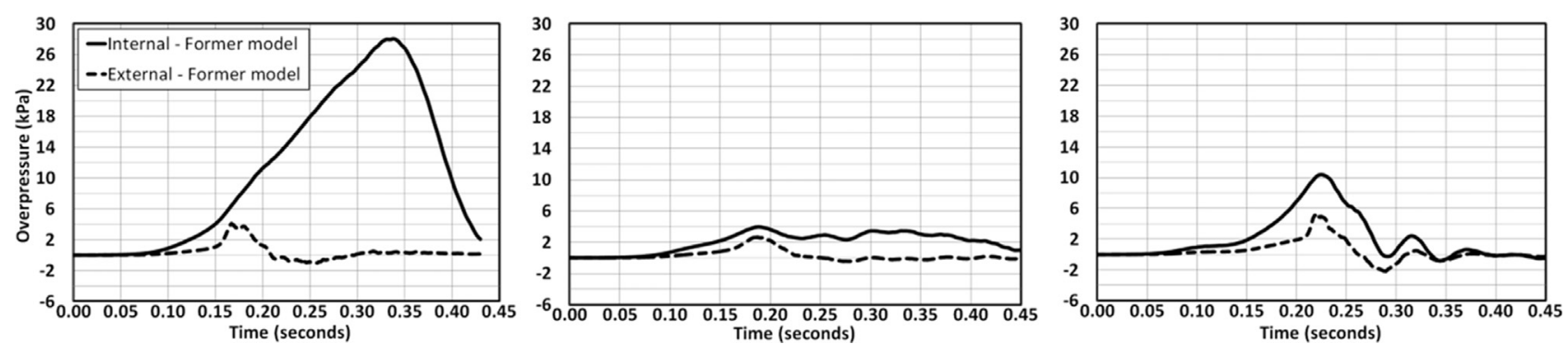

Fig. 2 - Former model internal and external pressure dynamics, central ignition case, $2.7 \mathrm{~m}^{2}$ vent (left); central ignition case, $5.4 \mathrm{~m}^{2}$ vent (centre); and back wall ignition case, $5.4 \mathrm{~m}^{2}$ vent (right).

experiments the external overpressures were comparable with the internal pressure. As shown in Fig. 2 the external pressures from the former model did not reach such levels.

This under-prediction was attributed to the absence of a combustion enhancing mechanism causing the intensification of the external deflagration.

\section{Modelling of Rayleigh-Taylor instability}

The influence of Rayleigh-Taylor (RT) instability during vented deflagrations has been investigated by a number of authors. Additionally, Rayleigh's criterion has been applied to actively control combustion instabilities in propulsion systems [17]. The growth of this instability has been found to occur most prominently as the flame accelerates through the vent [18] and also close to the vent following the expulsion of the hot combustion gases [19]. Additionally, following authors' previous work [3], the flow conditions required for the growth of RT instability were identified following the application of the former model to analyse the experiments described in Ref. [4]. This result provided the basis for the inclusion of RT instability during the simulation of the present vented deflagration scenarios.

\section{Time-dependent RT instability model}

Rayleigh-Taylor instability was first described by Lord Rayleigh [20] and by Sir G. Taylor [21]. It occurs at the interface between two fluids of different densities, subjected to acceleration in the direction from the lighter to the heavier. Accelerations in the flow, as described by Zeldovich et al. [22], may vary periodically in magnitude and sign and as such can have a stabilizing and destabilizing effect on the flame front. Additionally, following the experimental observations described in Ref. [18] it has been assumed that the flame front takes on a needle-like structure when the RT instability becomes dominant. The RT instability factor, Fig. 3, will take the form of the ratio between the surface areas of the slanted side of this conic shape, $S_{1}$, and the flat circular base, $S_{2}$.

The growth of the amplitude of the perturbation is described according to $h_{t}=h_{t-\Delta t} \cdot e^{\omega t}$ [22]. The amplitude of the perturbation will increase if acceleration is in the direction from lighter to heavier. Acceleration calculated for use within the introduced RT model is defined as flow acceleration in the direction normal to the flame front. Annihilation of the flame surface at cusps [15], termed the 'sink', as well as a reduction in the amplitude if acceleration occurs in the opposite direction controls the reduction of the RT wrinkling factor. The equation describing this growth and removal of the RT amplitude can be written as:

$h_{\mathrm{t}}=h_{\mathrm{t}-\Delta \mathrm{t}}\left(1+\omega_{\mathrm{t}} \cdot \Delta \mathrm{t}\right)-\alpha \cdot \mathrm{S}_{\mathrm{T}, \mathrm{t}}\left(\Xi_{\mathrm{RT}, \mathrm{t}}-1\right) \Delta \mathrm{t}$.

Wavelength and growth rate, as defined in Eqs. (5) and (7), are both dependent on acceleration, therefore for a particular value of acceleration there is a specific, corresponding, 'most unstable' wavelength [23]. From Ref. [23] wavelength is calculated according to:

$\lambda_{t}=4 \cdot \pi \cdot\left(\frac{\nu_{T, t}^{2}}{A c c_{t} \cdot A_{t}}\right)^{1 / 3}$,

where Atwood number, A, defined as the dimensionless density ratio is calculated using Eq. (6):

$A_{t}=\left(\rho_{u, t}-\rho_{b, t}\right) /\left(\rho_{u, t}+\rho_{b, t}\right), \rho_{u}>\rho_{b}$.

Growth rate is calculated using the classical equation outlined by many authors. Following substitution of Eq. (5) into the growth rate equation from Ref. [24], growth rate is written as:

$\omega_{t}=\sqrt{A_{t} \cdot \frac{2 \cdot \pi}{\lambda_{t}} \cdot A c c_{t}}=\sqrt{\frac{\left(A_{t} \cdot A c c_{t}\right)^{4 / 3}}{2 \cdot \nu_{T, t}^{2 / 3}}}$.

To take into account the change in acceleration, the amplitude at each timestep is re-scaled according to the value of wavelength (Eq. (5)) at the current and previous timestep.

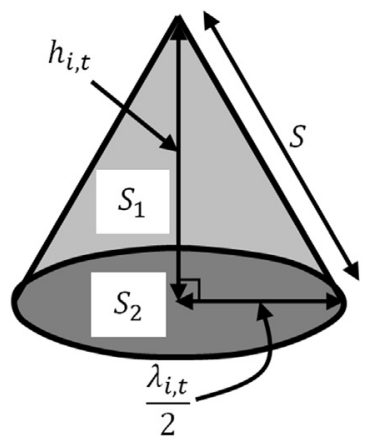

$$
\begin{aligned}
& \Xi_{R T}=\frac{S_{1}}{S_{2}}=\frac{\pi \cdot\left(\lambda_{i, t} / 2\right) \cdot S}{\pi \cdot\left(\lambda_{i, t} / 2\right)^{2}}=\frac{S}{\left(\lambda_{i, t} / 2\right)}, \\
& S=\sqrt{\left(\frac{\lambda_{i, t}}{2}\right)^{2}+h_{i, t}^{2}} . \\
& \Xi_{R T}=\sqrt{1+\left(\frac{h_{i, t}}{\lambda_{i, t} / 2}\right)^{2}}
\end{aligned}
$$

Fig. 3 - Simplified shape of an RT perturbed element of the flame front. 
This rescaling is carried out prior to the calculation of the updated amplitude described by Eq. (4). Eq. (4) contains an empirical coefficient, $\alpha$, associated with the 'sink' term, this coefficient is of the order of 1.0 and following parametric analysis is set to 0.75 . The final term that should be considered is a suitable value of the initial perturbation amplitude, which is calculated as a percentage of the wavelength following [25]:

$h_{0, t}=k_{h} \times \lambda_{t}$,

The key area of interest is the influence that the introduction of RT instability has on the intensity of the external deflagration. The instability itself is known to occur most prominently as the flame accelerates through the vent and also close to the vent following the expulsion of the hot combustion gases. Therefore in these areas, inside the chamber as the flame front begins to accelerate towards the vent and in the area outside the chamber surrounding the vent, the introduced RT mechanism is allowed to grow. In the remaining chamber volume $k_{h}$ is set to 0.001 in order to limit the growth of the RT perturbation. Following the calculation of the initial amplitude, within the flame front, amplitude is subsequently calculated according to Eq. (4). The values of $k_{h}$ and $\alpha$ selected during the simulations are provided in Table 1.

It should be noted that setting the value of $k_{h}$ to 0.5 (or 0.75) will lead to an increase in the minimum value of $S_{T}$ in the area where the introduced RT mechanism is allowed to grow. The selection of $k_{h}$ by the inverse problem method can be viewed as providing an adequate baseline from which the growth of the RT instability can occur. This was confirmed during model testing where the value of the $\Xi_{R T}$ parameter was set and locked to 1.80 (corresponding to $k_{h}=0.75$ ), and produced no noticeable difference in the recorded internal pressures.

Following an analysis of this procedure growth in the value of $\Xi_{R T}$, from the set minimum baseline value, was found to be reliant on and only encountered in areas where there was a sufficiently high concentration of acceleration in the unstable direction. For example, when considering the central ignition case with the $2.7 \mathrm{~m}^{2}$ vent, the flame reached and had significantly propagated into the area where $k_{h}$ has been seen to 0.75 prior to the production of the largest values of $\Xi_{R T}$ at $t=0.1735 \mathrm{~s}$, as shown in Fig. 6 .

Finally, the transport equation for the RT wrinkling factor, $\Xi_{R T}$ is written as:

$\frac{\partial \Xi_{R T}}{\partial t}+\left(U_{i}+S_{T, i}\right) \frac{\partial \Xi_{R T}}{\partial x_{i}}=S_{\Xi_{R T}}$.

It should be noted that Eq. (9) is similar to the transport equation derived in Ref. [26].
The unsteady term, is defined as:

$\frac{\partial \Xi_{R T}}{\partial t}=\frac{\Xi_{R T(\text { new })}-\Xi_{R T(\text { previous })}}{\Delta t}$.

The convection term, is defined as:

$$
\begin{aligned}
\left(U_{i}+S_{T, i}\right) \frac{\partial \Xi_{R T}}{\partial x_{i}}= & \left(U_{x}+S_{T, x}\right) \frac{\partial \Xi_{R T}}{\partial x}+\left(U_{y}+S_{T, y}\right) \frac{\partial \Xi_{R T}}{\partial y}+\left(U_{z}\right. \\
& \left.+S_{T, z}\right) \frac{\partial \Xi_{R T}}{\partial z} .
\end{aligned}
$$

As the source term in the transport equation to solve for $\Xi_{R T}$ (Eq. (9)) should describe the generation and suppression of the RT wrinkling factor at the flame front, within a given CV over time, the equation describing the source term is written in our model as:

$S_{\Xi_{R T}}=\frac{d \Xi_{R T}}{d h} \cdot \frac{d h}{d t}$

where $\quad \mathrm{d} \Xi_{\mathrm{RT}} / \mathrm{d} h=2 \cdot h_{\mathrm{t}} / \lambda_{\mathrm{t}} \sqrt{\left(\lambda_{\mathrm{t}} / 2\right)^{2}+h_{\mathrm{t}}^{2}} \quad$ and $\quad \mathrm{d} /$ $d t=h_{t} \cdot \omega_{t}-\alpha \cdot S_{T, t}\left(\Xi_{R T, t}-1\right)$.

It is worth stating that the authors of [5] have also developed their own in house CFD model to account for RT instability. Both these models solve an additional transport equation for the flame surface wrinkling due to RT instability, $\Xi_{R T}$ and utilise the same equation describing amplitude growth, as defined in Ref. [22]. However, the model described in Ref. [5] assumes that the amplitude of wrinkling is much smaller than a quarter wavelength [15], whereas the model described in this paper is based on the experimental observations outlined in Ref. [18] and as such allows amplitude to grow larger than wavelength. Also, in Ref. [5] the model assumes a constant value for wavenumber, and subsequently wavelength, whereas wavelength is calculated as per Eq. (5) in the model described in this paper and ultimately depends on acceleration.

\section{Simulation results following inclusion of the RT instability model}

Fig. 4 demonstrates that, following the introduction of the RT instability mechanism to the model, the simulation results have improved. In the $5.4 \mathrm{~m}^{2}$ vent cases the magnitude of the internal pressure peak associated with the external deflagration has been more closely replicated.

\section{Internal pressure dynamics}

The general shape of the pressure-time curves produced from Simulation 2 and Simulation 3 agree quite closely with the experimental results. In Simulation 2 and Simulation 3, the sharp pressure increase associated with the external defla gration has now been reproduced. Additionally in Simulation 2,

\begin{tabular}{|c|c|c|c|c|c|c|}
\hline \multirow[t]{3}{*}{ Simulation number } & \multirow{2}{*}{\multicolumn{2}{|c|}{ Experimental setup }} & \multicolumn{4}{|c|}{ Location } \\
\hline & & & \multicolumn{2}{|c|}{ Inside chamber } & \multicolumn{2}{|c|}{ Approaching vent \& outside chamber } \\
\hline & Vent size, $\mathrm{m}^{2}$ & Ignition & $k_{h}$ & $\alpha$ & $k_{h}$ & $\alpha$ \\
\hline 1 & 2.7 & Centre & 0.001 & 0.75 & 0.5 & 0.75 \\
\hline 2 & 5.4 & Centre & & & & \\
\hline 3 & 5.4 & Back wall & & & & \\
\hline
\end{tabular}

\section{Table 1 - Parameters specified within each simulation.}



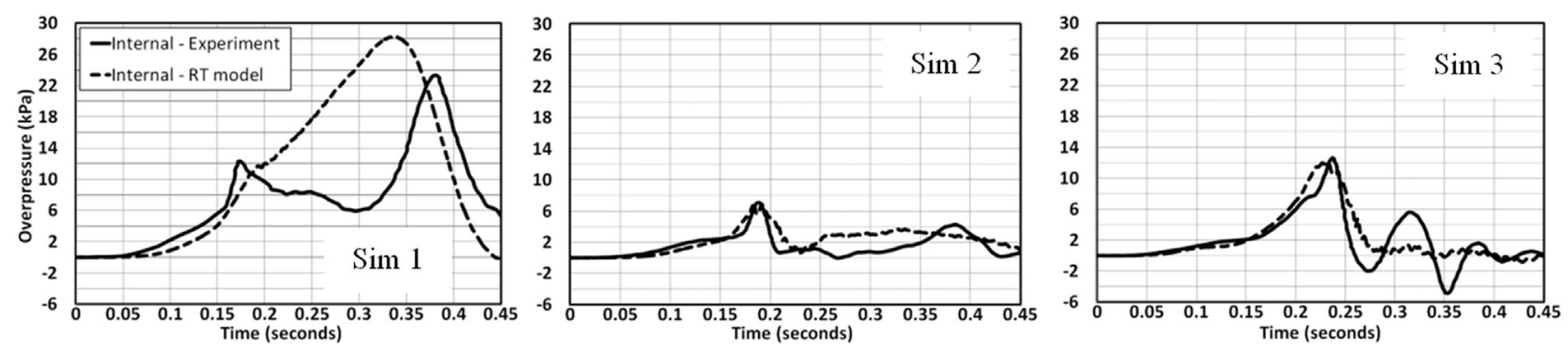

Fig. 4 - Comparison between experiment and RT model simulations, central ignition case, $2.7 \mathrm{~m}^{2}$ vent (left); central ignition case, $5.4 \mathrm{~m}^{2}$ vent (centre); and back wall ignition case, $5.4 \mathrm{~m}^{2}$ vent (right).

following this peak, the decrease in pressure to near atmospheric levels has been replicated. In Simulation 1 the internal pressure peak associated with the external deflagration is more visibly reproduced. However the simulation significantly over-predicts the internal chamber pressure prior to the second pressure peak. It is worth noting that the second peak is mainly associated with the acoustic instability related to the chamber parameters, its reproduction is beyond the scope of this preliminary study. The influence on the intensity of the external deflagration, due to the addition of the RT model, can be seen in Fig. 5.

External pressure dynamics

As the flame exits the vent it accelerates the colder unburned hydrogen/air mixture, leading to the observed increase in $\Xi_{R T}$. This increase in $\Xi_{R T}$ in the area surrounding the vent leads to an increase in flame surface area and ultimately the creation of the sharp external pressure peaks shown in Fig. 5.

The results shown in Figs. 4 and 5 obtained from Simulation 1 indicate that the addition of the RT model has not had the desired influence on the magnitude of the external deflagration. As such an additional simulation has been undertaken to investigate the influence of increasing the value of $k_{h}$ from 0.5 to 0.75 . The results from this simulation are shown in Fig. 6. All other parameters have been kept constant.

Internal and external pressure dynamics

The increase in $k_{h}$ during this simulation has led to an increase in the magnitude of the external deflagration, which in turn has led to a more pronounced internal pressure peak. Overall this has led to closer agreement with the experimental results.
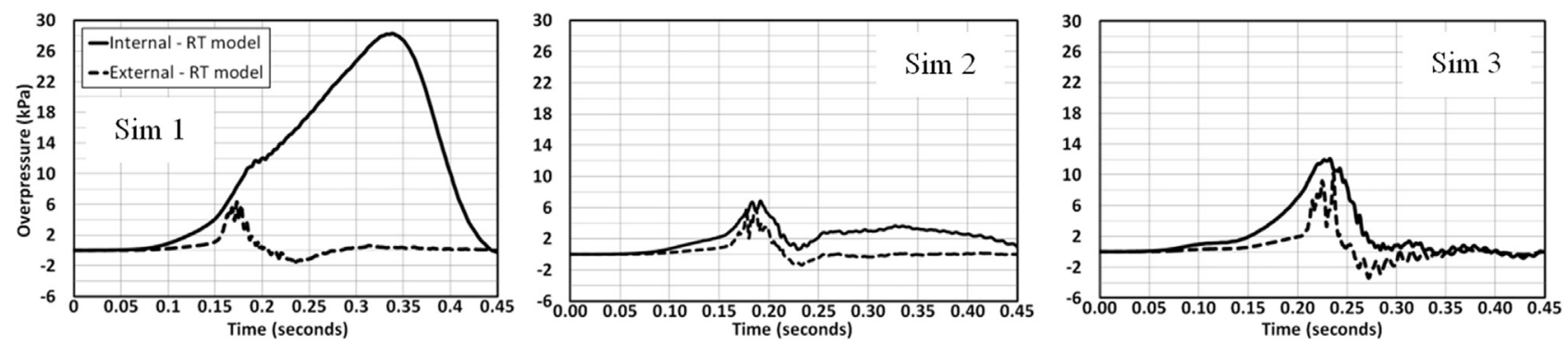

Fig. 5 - RT model internal and external pressure dynamics, central ignition case, $2.7 \mathrm{~m}^{2}$ vent (left); central ignition case, $5.4 \mathrm{~m}^{2}$ vent (centre); and back wall ignition case, $5.4 \mathrm{~m}^{2}$ vent (right).
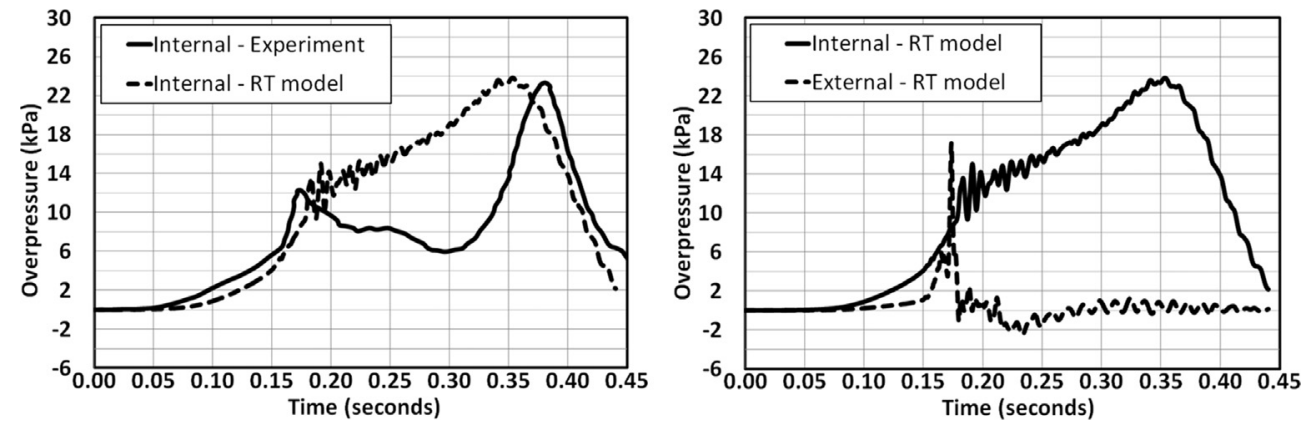

Fig. 6 - Central ignition case, $2.7 \mathrm{~m}^{2}$ vent, $k_{h}=0.75$ approaching the vent \& outside chamber: comparison between experiment \& RT model (left); and internal \& external pressure from RT model simulation (right). 
Prior to the addition of the RT instability model, Fig. 2, the external pressure was less than the internal pressure. Following the introduction of the RT model the intensity of the external deflagration has increased, decreasing the efficiency of the venting process. Overall, this resulted in the simulated pressure-time curves coming into closer agreement with their corresponding experimental observations.

\section{Conclusions}

Rayleigh-Taylor instability was identified as playing a major role in pressure build-up during the external deflagration encountered within large scale scenarios. A model representing this instability has been developed and added to the multi-phenomena turbulent burning velocity deflagration model. The influence of this mechanism was limited to the external deflagration only. This updated model was then tested against the pressure-time history data obtained from large scale experiments undertaken by FM Global.

The model has been implemented in the form of a separate transport equation for the $\Xi_{\mathrm{RT}}$ wrinkling factor, containing source and sink terms developed based on phenomenological considerations of Rayleigh-Taylor instability. Following the addition of this mechanism the intensity of the external deflagration was substantially increased. This had a significant influence on the internal pressure dynamics. The increased intensity of the external deflagration caused a decrease in the efficiency of the venting process, leading to an increase in the internal pressure. Following the fast dissipation of the external premixed combustion, the high pressure inside the chamber could be more efficiently vented. This process, now more closely captured, recreated the experimentally observed first pressure peak recorded during each experiment analysed.

The introduction of RT instability into the multiphenomena turbulent burning velocity deflagration model led to closer agreement between the simulated and experimental results. The addition of this mechanism was required in order to capture the main features and pressure transients associated with the coherent deflagrations that occurred. Therefore when considering the modelling of large scale vented deflagration scenarios, RT instability must be included as an SGS premixed combustion sub-model.

\section{REFEREN C E S}

[1] Molkov V. Fundamentals of hydrogen safety engineering, parts I \& II. Free download e-book, ISBN 978-87-403-0279-0., www.bookboon.com; 2012.

[2] Keenan J, Makarov D, Molkov V. Towards the implementation of Rayleigh-Taylor instability into the multiphenomena deflagration model. In: Proceedings of 7th ISFEH, USA; 2013. pp. 932-41.

[3] Makarov D, Verbecke F, Molkov V, Keenan J. On unresolved mechanisms of large scale deflagrations in complex geometries. In: Presented at the 6th ISFEH; 2010. pp. 93-103.
[4] Shirvill L, Royle M, Roberts T. Hydrogen releases ignited in a simulated vehicle refuelling environment. In: Presented at the 2nd ICHS, San Sebastian, Spain; 2007.

[5] Bauwens C, Chaffee J, Dorofeev S. Vented explosion overpressures from combustion of hydrogen and hydrocarbon mixtures. IJHE Feb. 2011;36(3):2329-36.

[6] Molkov V, Makarov D, Schneider H. LES modelling of an unconfined large-scale hydrogen-air deflagration. J Phys D Oct. 2006;39(20):4366-76.

[7] Prudnikov A. Combustion of homogeneous fuel-air mixtures in turbulent flows. Physical principles of the working process in combustion chambers of jet engines; 1967. pp. 244-336.

[8] Yakhot V, Orszag S. Renormalization group analysis of turbulence. I. Basic theory. J Sci Comput 1986;1(1):3-51.

[9] Pope S. Turbulent flows. Cambridge University Press; 2000.

[10] Yakhot V. Propagation velocity of premixed turbulent flames. Combust Sci Technol 1988;60:191-214.

[11] Babkin V. Private communication: Institute of Chemical Kinetics and Combustion, Siberian Branch, Russian Academy of Science. Novosibirsk, Russia: 2003.

[12] Gostintsev Y, Istratov A, Shulenin Y. Self-similar propagation of a free turbulent flame in mixed gas mixtures. Combust Explos Shock Waves 1989;24(5).

[13] Verbecke F. Formation and combustion of non-uniform hydrogen-air mixtures [PhD thesis]. Newtownabbey, N. Ireland, U.K.: HySAFER Centre, University of Ulster; 2009.

[14] Cooper M, Fairweather M, Tite J. On the mechanisms of pressure generation in vented explosions. Combust Flame 1986;65(1):1-14.

[15] Bauwens C, Dorofeev S. Effect of the external explosion on vented deflagrations. In: Presented at the 8th ISHPMIE, Yokohama, Japan; 2010.

[16] Harrison J, Eyre J. External explosions as a result of explosion venting. Combust Sci Technol 1987;52(1):91-106.

[17] Zinn B, Neumeier Y. Application of Rayleigh's criterion in active control of combustion instabilities. Arch Combust 1995;15(3/4):287-300.

[18] Tsuruda T, Hirano T. Growth of flame front turbulence during flame propagation across an obstacle. Combust Sci Technol 1987;51(4-6):323-8.

[19] Solberg D, Pappas J, Skramstad E. Observations of flame instabilities in large scale vented gas explosions. Symposium (International) on Combustion 1981;18(1):1607-14.

[20] Lord Rayleigh JWS. Investigation of the character of the equilibrium of an incompressible heavy fluid of variable density. In: Proceedings of the London Mathematical Society. vol. 14 1883. pp. 170-7.

[21] Taylor G. The instability of liquid surfaces when accelerated in a direction perpendicular to their planes, I. In: Proceedings of the Royal Society of London, vol. 201, series A, mathematical and physical sciences, no. 1065; Mar. 1950. pp. 192-6.

[22] Zeldovich Y, Barenblatt G, Librovich V, Makhviladze G. Mathematical theory of combustion and explosions. New York, NY, USA: Consultants Bur; 1985.

[23] Youngs D. Numerical simulation of turbulent mixing by Rayleigh-Taylor instability. Phys D Nonlinear Phenom Jul. 1984;12(1-3):32-44.

[24] Dimonte G, Ramaprabhu P, Youngs D, Andrews M, Rosner R. Recent advances in the turbulent Rayleigh-Taylor instability. Phys Plasmas 2005;12(056301):1-6.

[25] Tryggvason G. Numerical simulations of the Rayleigh-Taylor instability. J Comput Phys Apr. 1988;75(2):253-82.

[26] Weller H, Tabor G, Gosman A, Fureby C. Application of a flame-wrinkling LES combustion model to a turbulent mixing layer. Symp (Int) Combust 1998;1:899-907. 